\title{
Anisotropic behaviour of semiconducting tin monosulphoselenide single crystals
}

\author{
T H PATEL, RAJIV VAIDYA and S G PATEL* \\ Department of Physics, Sardar Patel University, Vallabh Vidyanagar 388 120, India
}

MS received 16 September 2002; revised 2 July 2003

\begin{abstract}
Single crystals of ternary mixed compounds of group IV-VI in the form of a series, $\mathrm{SnS}_{x} \mathrm{Se}_{1-x}$ (where $x=0,0.25,0.50,0.75$ and 1 ), have been grown using direct vapour transport technique. The grown crystals were characterized by the $\mathrm{X}$-ray diffraction analysis for their structural parameter determination. All the grown crystals were found to be orthorhombic. The microstructure analysis of the grown crystals reveals their layered type growth mechanism. From the Hall effect measurements Hall mobility, Hall coefficient and carrier concentration were calculated with all crystals showing $p$-type nature. The d.c. electrical resistivity measurements perpendicular to $c$-axis (i.e. along the basal plane) in the temperature range 303-453 $\mathrm{K}$ were carried out for grown crystals using four-probe method. The d.c. electrical resistivity measurements parallel to $c$-axis (i.e. perpendicular to basal plane) in the temperature range 303-453 K were carried out for the same crystals. The electrical resistivity measurements showed an anisotropic behaviour of electrical resistivity for the grown crystals. The anisotropic behaviour and the effect of change in stoichiometric proportion of $S$ and Se content on the electrical properties of single crystals of the series, $\mathrm{SnS}_{x} \mathrm{Se}_{1-x}$ (where $x=0,0.25,0.50,0.75$ and 1), is presented systematically.
\end{abstract}

Keywords. Crystal growth; layered structure; resistivity; anisotropy; stacking disorder.

\section{Introduction}

Sulphides and selenides of the fourth group metals like germanium and tin ( $\mathrm{GeS}, \mathrm{GeSe}, \mathrm{SnS}$ and $\mathrm{SnSe}$ ) form an interesting family of layered compounds. These compounds are considered intermediate between the three dimensional and the two dimensional materials. They all exhibit an orthorhombic structure belonging to space group $D_{16}^{2 h}(P c m n)$ which can be described as distortion of the simple cubic structure of $\mathrm{NaCl}$ (Eymerd and Otto 1977; Grandke and Ley 1977; Shalvoy et al 1977; Park and Srivastava 1980; Valiukonis et al 1983; Taniguchi et al 1990). These lamellar compounds have attracted considerable attention because of their important properties in the field of optoelectronics (Logothetidis and Polatoglou 1987), holographic recording systems (Valiukonis et al 1986), electronic switching (Bletskan et al 1976; Singh and Bedi 1990) and infrared production and detection (Bedi et al 1992). Among these, the binary IV-VI compounds, $\mathrm{SnSe}$ and $\mathrm{SnS}$, crystallize in a distorted $\mathrm{NaCl}$ structure (Chandrashekhar et al 1977; Valiukonis et al 1984). These crystals are formed by tightly bound double layers of cation ( $\mathrm{Sn}$ ) and anion ( $\mathrm{S}$ or $\mathrm{Se}$ ) atoms stacked along the longest axis. The lattice structure of these materials can be viewed as a severely distorted $\mathrm{NaCl}$ structure. Each atom has three strongly bonded neighbours within

\footnotetext{
*Author for correspondence
}

its own layer and three more distant weakly bonded neighbours one of which lies in an adjacent layer. The bonding between the layers is weak being of Van der Waal's type and therefore they can be easily cleaved in the (001) plane (Garg et al 1983). From this fact one might expect them to exhibit the typical anisotropy of electrical properties i.e. conductivity or mobility of a layered structure. Mechanically, single crystals of these layered materials behave extremely two-dimensional. Although layered materials are indeed anisotropic, there is a great variation in the anisotropy ratio among them. In some cases anisotropy factor up to $10^{6}$ have been reported (Agarwal et al 1983). Since most of the semiconductor applications are governed by the electrical properties of the materials, the electrical properties of the IV-VI compounds ( $\mathrm{GeS}$, GeSe, $\mathrm{SnS}$ and $\mathrm{SnSe}$ ) have been carried out by different investigators (Maier and Daniel 1977; Clemen et al 1978; Yue et al 1981; Akimchenco and Rasulova 1983; Nagard et al 1990). Most of these studies are nearly confined to investigations of electrical properties along the basal plane and very few of them report the interesting question of electrical transport along the $c$-axis. However, in order to understand the various conduction properties, immediate to those of binary system, ternary mixed compounds (solid solutions) were grown in the form of single crystals. Although the end members of the series ( $\mathrm{SnSe}$ and $\mathrm{SnS}$ ) have been studied thoroughly (Car et al 1978; Elkorashy 1986, 1987, 1989a,b, 1990a,b; Bhatt et al 1989; Siddiqui and Desai 1993, 1994; Agarwal et al 1994; Vyas et al 1995a,b; 
Agarwal 1998), very few experimental results are available at present for the middle members formed with one cation ( $\mathrm{Sn}$ ) and two anions ( $\mathrm{S}$ and $\mathrm{Se}$ ) in the form of a series, $\mathrm{SnS}_{x} \mathrm{Se}_{1-x}$ with $0<x<1$. A systematic study on the anisotropic behaviour of d.c. electrical resistivity of mixed single crystals with composition, $\mathrm{SnS}_{x} \mathrm{Se}_{1-x}$ (where $x=0,0 \cdot 25,0 \cdot 50,0 \cdot 75$ and 1 ), have been reported in this paper.

\section{Experimental}

Single crystals of the series, $\mathrm{SnS}_{x} \mathrm{Se}_{1-x}$, obtained by the direct vapour transport technique were characterized by $\mathrm{X}$-ray diffraction using Philips X-ray Diffractometer PW 1820 employing $\mathrm{CuK}_{\alpha}$ radiation in the $2 \theta$ range of $15-95^{\circ}$. The $d$-values obtained for $\mathrm{SnSe}, \mathrm{SnS}_{0.25} \mathrm{Se}_{0.75}$ and $\mathrm{SnS}_{0.5} \mathrm{Se}_{0.5}$ are presented in table 1 and those obtained for $\mathrm{SnS}_{0.75} \mathrm{Se}_{0.25}$ and $\mathrm{SnS}$ are presented in table 2. The values of the lattice parameters determined from the analysis of $\mathrm{X}$-ray diffractograms of each crystal are shown in table 3 . For the determination of chemical composition of the elements, energy dispersive analysis of X-ray (EDAX) measurements were carried out. The Hall effect measurements were carried out for all grown crystals at room temperature using Van der Pauw method. The values of Hall mobility, Hall coefficient and carrier concentration determined from the Hall effect measurements are represented in table 3.

The electrical resistivity perpendicular to $c$-axis in the temperature range $303-453 \mathrm{~K}$ was measured using fourprobe set-up developed by Scientific Equipments, Roorkee, India. The set-up consists of four collinear and equally spaced spring loaded four probes coated with zinc at the tips to ensure good electrical contact with the crystal. For voltage and current measurements suitable leads are provided. A small oven has been provided to facilitate measurements at various temperatures. A highly regulated constant current source (Scientific Solutions, Mumbai) specially designed to provide the varying current has been used. For $\mathrm{SnSe}, \mathrm{SnS}_{0.25} \mathrm{Se}_{0.75}$ and $\mathrm{SnS}_{0.5} \mathrm{Se}_{0.5}$, current in the range 1-5 mA was enough whereas for $\mathrm{SnS}_{0.75} \mathrm{Se}_{0.25}$ and $\mathrm{SnS}$, current of $10 \mathrm{~mA}$ was required for the resistivity mea-

Table 1. Comparison of $d$-values for $\mathrm{SnSe}, \mathrm{SnS}_{0.25} \mathrm{Se}_{0.75}$ and $\mathrm{SnS}_{0.5} \mathrm{Se}_{0.5}$.

\begin{tabular}{|c|c|c|c|c|}
\hline \multirow{2}{*}{$\begin{array}{l}d(\AA) \\
(\text { JCPDS-1998) }\end{array}$} & \multirow{2}{*}{$\begin{array}{l}\text { Reflections } \\
\quad(h k l)\end{array}$} & \multicolumn{3}{|c|}{$d(\AA)$ observed } \\
\hline & & $\mathrm{SnSe}$ & $\mathrm{SnS}_{0.25} \mathrm{Se}_{0.75}$ & $\mathrm{SnS}_{0.5} \mathrm{Se}_{0.75}$ \\
\hline $3 \cdot 514$ & 102 & $3 \cdot 507$ & $3 \cdot 510$ & $3 \cdot 498$ \\
\hline $3 \cdot 366$ & 012 & $3 \cdot 361$ & $3 \cdot 360$ & $3 \cdot 322$ \\
\hline 3.033 & 110 & 3.030 & 3.003 & 3.003 \\
\hline 2.933 & 111 & 2.929 & 2.930 & $2 \cdot 930$ \\
\hline $2 \cdot 874$ & 004 & $2 \cdot 871$ & $2 \cdot 870$ & $2 \cdot 856$ \\
\hline 1.832 & 115 & 1.831 & 1.831 & 1.817 \\
\hline 1.437 & 018 & 1.436 & 1.436 & 1.427 \\
\hline
\end{tabular}

surements along the basal plane. The electrical resistivity measurements parallel to $c$-axis were carried out using the experimental set-up designed by our University Scientific Instrument Centre. The crystal was mounted on a sample holder, which was then inserted into a sample chamber. The temperature of the crystal was increased by introducing the sample chamber into a vertical single zone furnace.

\section{Results and discussion}

The values of lattice parameters obtained for $\mathrm{SnSe}$ and SnS single crystals are compared and found in agreement with those reported earlier by different investigators (Agarwal et al 1994; Okazaki and Ueda 1956). The effect of the stoichiometric proportion of $\mathrm{S}$ and Se content on the lattice parameters can be seen in table 3. Also table 3 indicates that the lattice parameters of the selenium rich compounds are close to those of $\mathrm{SnSe}$ whereas those for sulphur rich compound are close to that of SnS. The variations of the lattice parameters are very similar to those observed (Albers et al 1962) for the mixed crystals of tin monosulphoselenides.

From the data shown in table 3 , it can be seen that the values of Hall parameters are affected by the variation of stoichiometric proportion of $\mathrm{S}$ and Se content. The sign of the Hall coefficient suggests that all grown crystals are of $p$-type. Also the room temperature resistivity along the basal plane and the Hall coefficient increases whereas mobility and carrier concentration decreases as the stoichiometric proportion of sulphur increases in the single crystals of the series, $\mathrm{SnS}_{x} \mathrm{Se}_{1-x}$ (where $x=0,0 \cdot 25,0 \cdot 50$, 0.75 and 1). These variations can be understood since the nature of chemical bonding between cation (Sn) and anion ( $\mathrm{S}$ and $\mathrm{Se}$ ) changes as the stoichiometry of $\mathrm{S}$ and Se content changes. The results of the EDAX report shown in table 4 , confirms that the stoichiometry of the elements has been maintained in the grown crystals.

The variation of $\log$ of electrical resistivity parallel to $c$-axis and perpendicular to $c$-axis in the temperature range $303-453 \mathrm{~K}$ are shown in figures 1 and 2, respectively. The decrease in electrical resistivity with increase

Table 2. Comparison of $d$-values for $\mathrm{SnS}_{0.75} \mathrm{Se}_{0.25}$ and $\mathrm{SnS}$.

\begin{tabular}{|c|c|c|c|}
\hline \multirow{2}{*}{$\begin{array}{l}d(\AA) \\
(\text { JCPDS-1998) }\end{array}$} & \multirow{2}{*}{$\begin{array}{l}\text { Reflections } \\
\quad(h k l)\end{array}$} & \multicolumn{2}{|c|}{$d(\AA)$ observed } \\
\hline & & $\mathrm{SnS}_{0.75} \mathrm{Se}_{0.25}$ & $\mathrm{SnS}$ \\
\hline $2 \cdot 832$ & 111 & $2 \cdot 836$ & 2.837 \\
\hline $2 \cdot 763$ & 004 & - & 2.798 \\
\hline $2 \cdot 165$ & 200 & $2 \cdot 159$ & - \\
\hline $2 \cdot 015$ & 202 & $2 \cdot 015$ & 2.024 \\
\hline 1.901 & 210 & 1.900 & - \\
\hline $1 \cdot 874$ & 211 & - & 1.874 \\
\hline $1 \cdot 808$ & 120 & $1 \cdot 804$ & - \\
\hline 1.718 & 122 & 1.715 & 1.712 \\
\hline
\end{tabular}


in temperature suggests the semiconducting nature of the grown crystals. Using the resistivity values, anisotropy ratio was calculated using the relation

$$
\gamma=\rho_{\|} / \rho_{\perp}
$$

where $\rho_{\|}$is the resistivity parallel to $c$-axis and $\rho_{\perp}$ the resistivity perpendicular to $c$-axis. The anisotropy ratio was determined at different temperatures in the range 303$453 \mathrm{~K}$ for all grown crystals. Figure 3 shows the variation of $\log$ of anisotropy ratio with reciprocal of temperature for each crystal. The anisotropy ratio increases as the temperature decreases for all the crystals.

For the materials, which are intermediate between two and three dimensions, there is an anisotropy of strength

Table 3. Results obtained from X-ray diffractograms, resistivity and Hall effect measurements for the single crystals of the series, $\mathrm{SnS}_{x} \mathrm{Se}_{1-x}$ (where $x=0,0 \cdot 25,0 \cdot 50,0 \cdot 75$ and 1$)$.

\begin{tabular}{|c|c|c|c|c|c|}
\hline Parameter & $\mathrm{SnSe}$ & $\mathrm{SnS}_{0 \cdot 25} \mathrm{Se}_{0 \cdot 75}$ & $\mathrm{SnS}_{0.5} \mathrm{Se}_{0 \cdot 5}$ & $\mathrm{SnS}_{0.75} \mathrm{Se}_{0 \cdot 25}$ & $\mathrm{SnS}$ \\
\hline$a(\AA)$ & $4 \cdot 435 \pm 0.008$ & $4 \cdot 434 \pm 0 \cdot 012$ & $4 \cdot 427 \pm 0 \cdot 002$ & $4 \cdot 317 \pm 0 \cdot 001$ & $4 \cdot 33 \pm 0.006$ \\
\hline$b(\AA)$ & $4 \cdot 152 \pm 0 \cdot 012$ & $4 \cdot 142 \pm 0 \cdot 013$ & $4.088 \pm 0.071$ & $4.005 \pm 0.001$ & $3 \cdot 976 \pm 0.005$ \\
\hline$c(\AA)$ & $11 \cdot 485 \pm 0 \cdot 007$ & $11 \cdot 481 \pm 0 \cdot 010$ & $11 \cdot 424 \pm 0.006$ & $11 \cdot 251 \pm 0 \cdot 002$ & $11 \cdot 196 \pm 0 \cdot 004$ \\
\hline Resistivity, $\rho_{\lrcorner}$, at $300 \mathrm{~K}(\Omega \cdot \mathrm{cm})$ & $2 \cdot 04$ & $2 \cdot 10$ & 4.89 & $20 \cdot 55$ & $53 \cdot 43$ \\
\hline Hall coefficient, $R_{\mathrm{H}}\left(\mathrm{cm}^{3} \mathrm{cb}^{-1}\right)$ & 255 & 258 & 490 & 1705 & 2547 \\
\hline Type & $p$ & $p$ & $p$ & $p$ & $p$ \\
\hline Mobility, $\mu_{\mathrm{H}}\left(\mathrm{cm}^{2} / \mathrm{V} \mathrm{s}\right)$ & 125 & 123 & 100 & 83 & 48 \\
\hline Carrier concentration, $\eta\left(\mathrm{cm}^{-3}\right)$ & $2.48 \times 10^{16}$ & $2.41 \times 10^{16}$ & $1.29 \times 10^{16}$ & $3.04 \times 10^{15}$ & $2.68 \times 10^{15}$ \\
\hline
\end{tabular}

Table 4. The EDAX data for $\operatorname{SnS}_{x} \mathrm{Se}_{1-x}(x=0,0 \cdot 25,0 \cdot 5,0 \cdot 75$ and 1$)$ single crystals.

\begin{tabular}{|c|c|c|c|c|c|c|}
\hline \multirow[b]{2}{*}{ Composition } & \multicolumn{3}{|c|}{$\begin{array}{l}\text { Wt }(\%) \text { of the elements obtained } \\
\text { from EDAX }\end{array}$} & \multicolumn{3}{|c|}{$\begin{array}{l}\text { Wt }(\%) \text { of elements taken for } \\
\text { the crystal growth }\end{array}$} \\
\hline & $\mathrm{Sn}$ & S & $\mathrm{Se}$ & $\mathrm{Sn}$ & $S$ & $\mathrm{Se}$ \\
\hline $\mathrm{SnSe}$ & $56 \cdot 57$ & - & $43 \cdot 43$ & $60 \cdot 05$ & - & 39.95 \\
\hline $\mathrm{SnS}_{0.25} \mathrm{Se}_{0.75}$ & $59 \cdot 36$ & $2 \cdot 86$ & $37 \cdot 78$ & $63 \cdot 87$ & $4 \cdot 25$ & 31.87 \\
\hline $\mathrm{SnS}_{0.5} \mathrm{Se}_{0.5}$ & $65 \cdot 92$ & $10 \cdot 35$ & $23 \cdot 73$ & $68 \cdot 75$ & $8 \cdot 75$ & $22 \cdot 5$ \\
\hline $\mathrm{SnS}_{0.75} \mathrm{Se}_{0.25}$ & 63.98 & $17 \cdot 68$ & $18 \cdot 33$ & 73 & $14 \cdot 75$ & $12 \cdot 25$ \\
\hline $\mathrm{SnS}$ & $54 \cdot 55$ & $45 \cdot 45$ & - & $78 \cdot 73$ & $21 \cdot 27$ & - \\
\hline
\end{tabular}

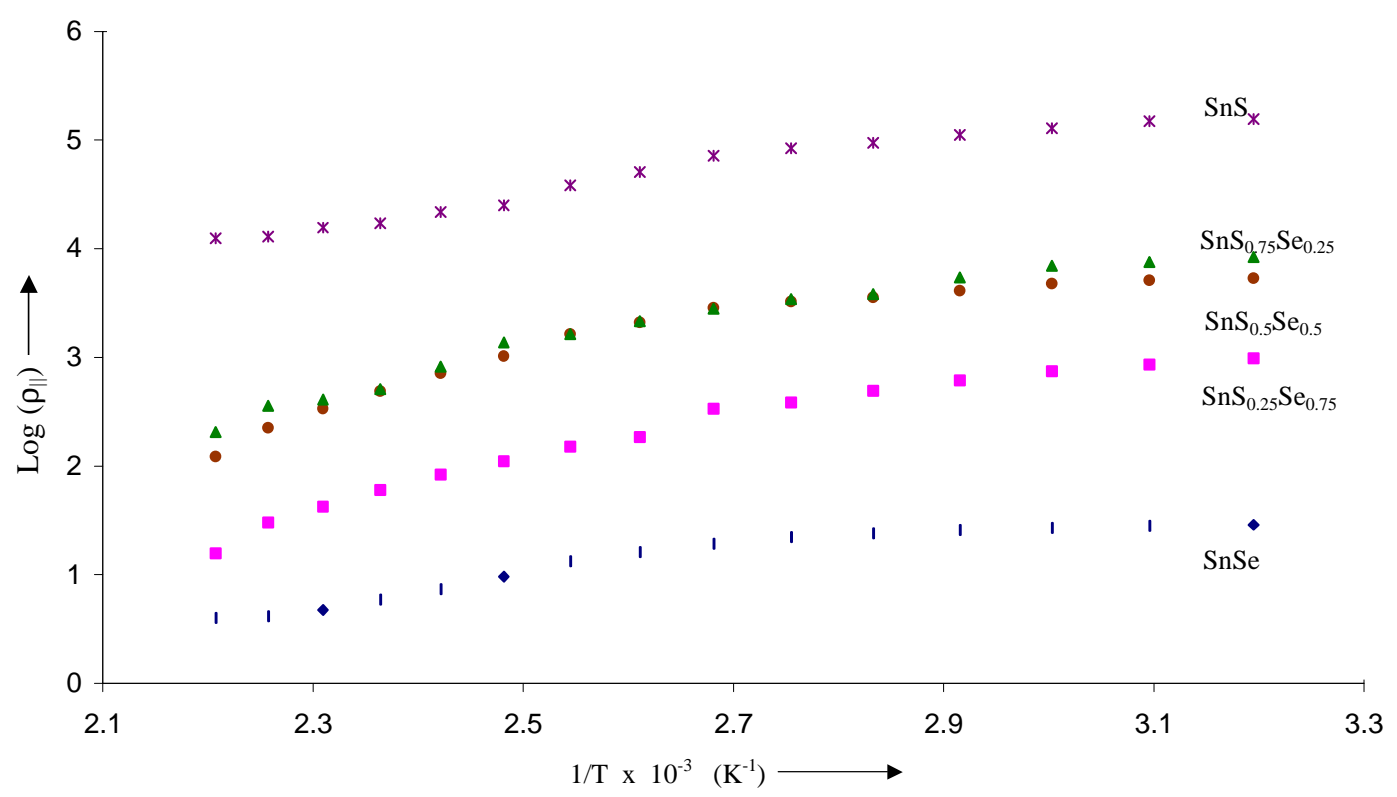

Figure 1. The variation of $\log$ of resistivity parallel to $c$-axis with reciprocal of temperature for the single crystals of the series, $\operatorname{SnS}_{x} \mathrm{Se}_{1-x}$ (where $x=0,0 \cdot 25,0 \cdot 50,0 \cdot 75$ and 1$)$. 
of the bonds between atoms. Application of temperature or chemical alloying causes greater changes in the lengths of the weaker bonds than those of stronger ones (Peters and McNeil 1990). This type of anisotropy behaviour is an interesting question for the strongly layered materials and it can also be explained as an effect of stacking disorder i.e. effect of a nonperiodic stacking sequence. Since the stacking-fault energy in layered materials is small, real crystals grown at high temperatures usually exhibit a non- periodic stacking sequence (Maschke and Schmid 1975). The disorder produced by the stacking faults is sufficient to localize the electron states normal to the layer. While considering the stacking between the adjacent layers, the whole crystal always remains invariant under the primitive translations parallel to the layers. So the d.c. transport parallel to layers is not affected by the presence of stacking disorder. However, the variation of resistivity along the basal plane is attributed to the change in nature

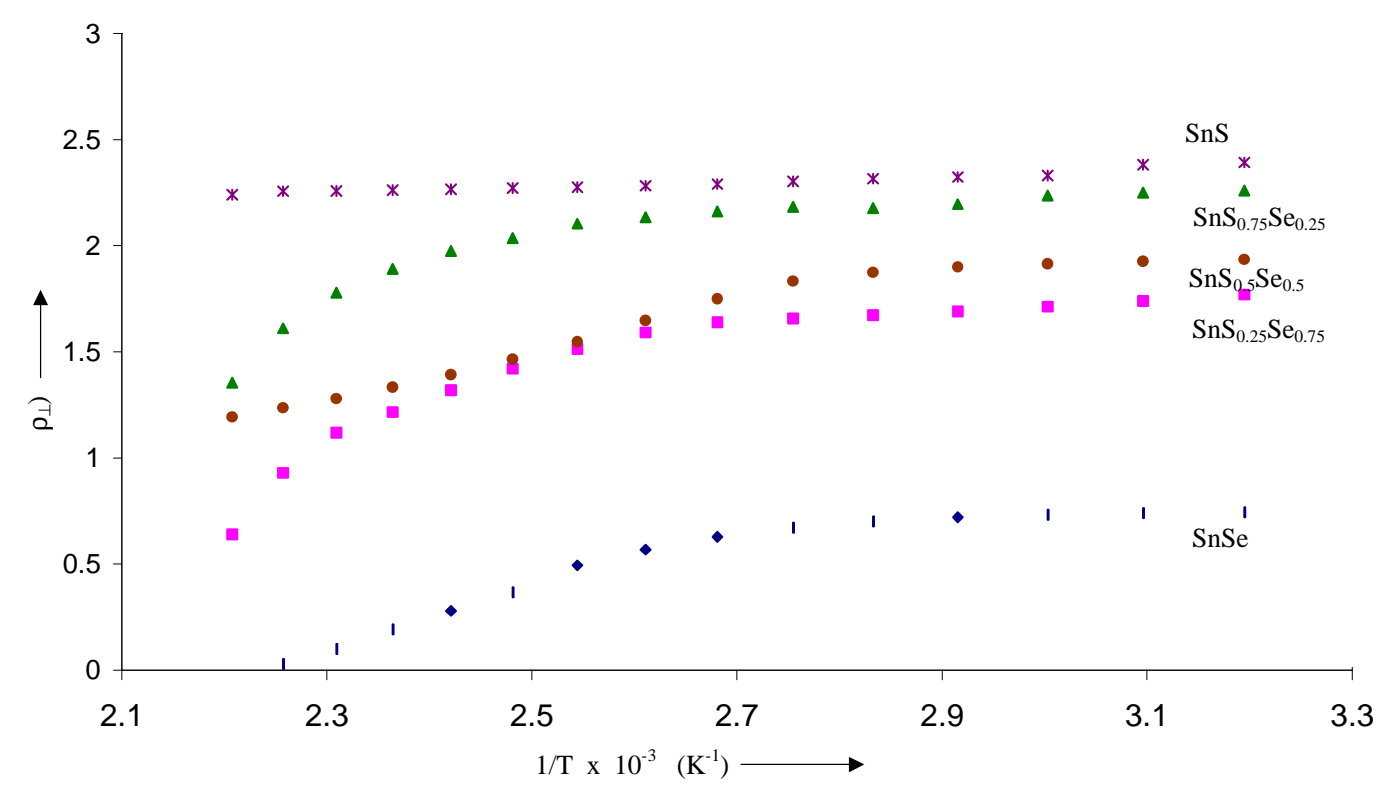

Figure 2. The variation of $\log$ of resistivity perpendicular to $c$-axis with reciprocal of temperature for the single crystals of the series, $\mathrm{SnS}_{x} \mathrm{Se}_{1-x}$ (where $x=0,0 \cdot 25,0 \cdot 50,0 \cdot 75$ and 1).

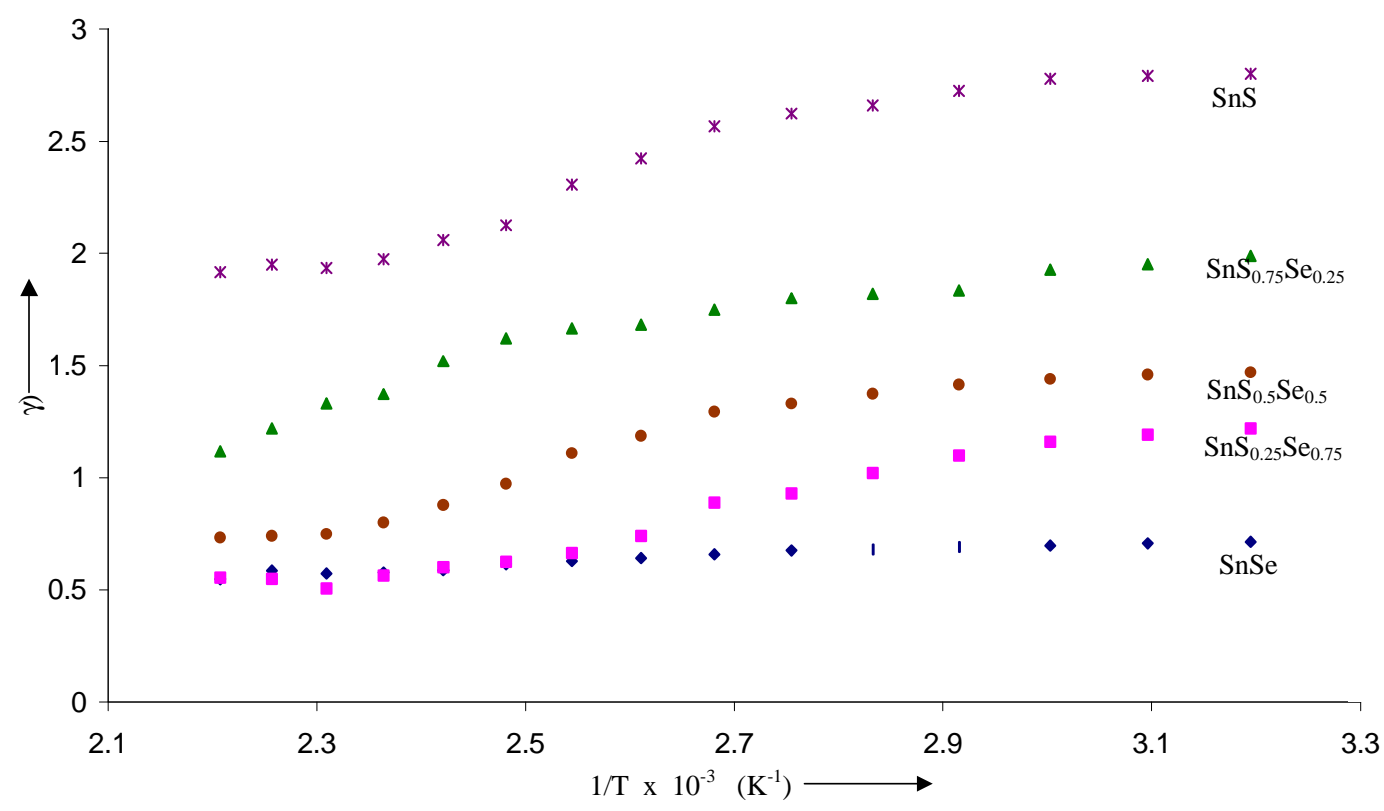

Figure 3. The variation of log of anisotropy ratio with reciprocal of temperature for the single crystals of the series, $\mathrm{SnS}_{x} \mathrm{Se}_{1-x}$ (where $x=0,0 \cdot 25,0 \cdot 50,0 \cdot 75$ and 1 ). 
of chemical bonding between the cation $(\mathrm{Sn})$ and anion ( $\mathrm{S}$ and $\mathrm{Se}$ ). Layered crystals often show predominance of stacking faults (Trigunayat 1971). Perpendicular to the layers, however, there is a probability of transport due to the localization of the electron states because of the presence of stacking faults. This will therefore give rise to a fairly large amount of conduction parallel to $c$-axis. Further the amount of conduction will be more for the crystals where the likelihood of stacking faults is more. The observed values of carrier concentration as well as mobility decrease with increase in sulphur content thereby suggesting a decrease in electrical transport. The increase in anisotropy ratio can be understood better from the data shown in table 3. However, according to Maschke and Schmid (1975) phenomenon of conduction along $c$-axis is formally a hopping process. It probably occurs in these crystals via a large overlap between states, which extend over many layers.

\section{Conclusions}

(I) The layered type single crystals of ternary mixed compound with one cation $(\mathrm{Sn})$ and two anions ( $\mathrm{S}$ and $\mathrm{Se}$ ) in the form of a series, $\mathrm{SnS}_{x} \mathrm{Se}_{1-x}$ (where $x=0,0 \cdot 25$, $0.50,0.75$ and 1 ) have been grown successfully using a direct vapour transport technique.

(II) The X-ray diffraction analysis indicates that the mixed crystals of composition, $\mathrm{SnS}_{x} \mathrm{Se}_{1-x}$, have the same orthorhombic crystal structure as $\mathrm{SnSe}$ and $\mathrm{SnS}$. No superstructure was observed.

(III) The lattice parameters along three crystallographic axes vary almost linearly with composition. The lattice parameters of the selenium rich compounds are close to that of SnSe whereas those for sulphur rich compounds are close to that of $\mathrm{SnS}$.

(IV) The sign of the Hall coefficient suggests that all grown crystals are of $p$-type. The resistivity and the Hall coefficient increase whereas mobility and carrier concentration decrease as the stoichiometric proportion of sulphur increases in the single crystals of the series, $\mathrm{SnS}_{x} \mathrm{Se}_{1-x}$ (where $x=0,0.25,0.50,0.75$ and 1 ).

(V) The electrical resistivity perpendicular to $c$-axis as well as parallel to $c$-axis decreases with increase in temperature for all grown crystals suggesting their semiconducting nature in the temperature range 303-453 K.

(VI) The anisotropy ratio increases with decrease in temperature as well as with the increase in sulphur content in the single crystals of the series, $\mathrm{SnS}_{x} \mathrm{Se}_{1-x}$ (where $x=0$, $0 \cdot 25,0 \cdot 50,0 \cdot 75$ and 1$)$.

(VII) The increase in anisotropy ratio can be attributed to decrease in conduction along $c$-axis due to decrease in presence of stacking disorder as the sulphur content increases in the single crystals of the series, $\mathrm{SnS}_{x} \mathrm{Se}_{1-x}$ (where $x=0,0.25,0.50,0.75$ and 1 ).

(VIII) The increase in anisotropy ratio can be attributed to the change in bond lengths between the anion and cation as the stoichiometric proportion of sulphur and selenium changes in the single crystals of the series, $\mathrm{SnS}_{x} \mathrm{Se}_{1-x}$ (where $x=0,0 \cdot 25,0 \cdot 50,0.75$ and 1 ).

\section{Acknowledgements}

The authors are indebted to DAE-BRNS for providing financial assistance in the form of a Research Project Sanction No. 99/37/28-BRNS/1004, for carrying out this work. The authors are very grateful to Prof. P D Patel and Prof. A R Jani for their valued guidance and comments.

\section{References}

Agarwal A 1998 J. Cryst. Growth 183347

Agarwal A, Patel P D and Laxminarayan D 1994 J. Cryst. Growth 142344

Agarwal M K, Patel P D and Vijayan O 1983 Phys. Status Solidi A79 103

Akimchenco I P and Rasulova G K 1983 Sov. Phys. Solid State 251514

Albers W, Hass C, Ober H, Schrodder G R and Wasscher J D 1962 J. Phys. Chem. Solids 23215

Bedi R K, Gopalan B S V and Majhi J 1992 Conference on the physics and technology of semiconductor devices and integrated circuits (SPIE Publications) p. 104

Bhatt V P, Gireesan K and Pandya G R 1989 J. Cryst. Growth 96649

Bletskan D I, Taran V I and Sichka M Yu 1976 Ukr. Fiz. Zh. 21 1436

Car R, Ciucci G and Quartapelle L 1978 Phys. Status Solidi B86 471

Chandrashekhar H R, Humphreys U and Cardona M 1977 Phys. Rev. B15 2177

Clemen C, Saldhana X I, Munz P and Bucher E 1978 Phys. Status Solidi A49 437

Elkorashy A M 1986 J. Phys. Chem. Solids 47497

Elkorashy A M 1987 Chemitronics 176

Elkorashy A M 1989a Semicond. Sci. Technol. 4382

Elkorashy A M 1989b J. Phys. Chem. Solids 50893

Elkorashy A M 1990a J. Phys. Chem. Solids 51289

Elkorashy A M 1990b Phys. Status Solidi B159 903

Eymerd and Otto A 1977 Phys. Rev. B16 1616

Garg A K, Jain A K and Agnihotri O P 1983 J. Pure \& Appl. Phys. 21276

Grandke T and Ley L 1977 Phys. Rev. B16 832

Logothetidis S and Polatoglou H M 1987 Phys. Rev. B36 7491

Maier H and Daniel D R 1977 J. Electron. Mater. 6693

Maschke K and Schmid Ph. 1975 Phys. Rev. B12 4312

Nagard N Le, Clement C Levy, Katty A and Lieth R M A 1990 Mater. Res. Bull. 25495

Okazaki A and Ueda I 1956 J. Phys. Soc. Jap. 11470

Park A W and Srivastava G P 1980 Phys. Status Solidi B101 K31

Peters M J and McNeil L E 1990 Phys. Rev. B41 5893

Shalvoy R B, Fisher G B and Stiles P J 1977 Phys. Rev. B15 2021 
Siddiqui S S and Desai C F 1993 Cryst. Res. Technol. 28 1169

Siddiqui S S and Desai C F 1994 J. Mater. Sci. Lett. 13512

Singh J P and Bedi R K 1990 J. Appl. Phys. 682776

Taniguchi M, Johnson R L J and Cardona M 1990 Phys. Rev. B42 3634

Trigunayat G C 1971 Phys. Status Solidi (a)4 281

Valiukonis G, Gashimzade F M, Gussienova D A, Krivaite G, Kulibekov A M, Orudzhev G S and Sileika A 1983 Phys. Status Solidi B117 81
Valiukonis G, Gashimzade F M, Guseinova D A, Krivaite G, Mamedov M M and Sileika A 1984 Phys. Status Solidi B122 623

Valiukonis G, Guseinova D A and Sileika A 1986 Phys. Status Solidi B135 299

Vyas S M, Pandya G R, Desai C F and Amin C T 1995a Cryst. Res. Technol. 30 PK78

Vyas S M, Pandya G R and Desai C F 1995b Indian J. Pure \& Appl. Phys. 33191

Yue Y G, Yue A S and Stafsudd O M Jr 1981 J. Cryst. Growth 54248 